\title{
Changes after Splenectomy of Plasma Protein Pattern in Banti's Syndrome*
}

\author{
Toshio Sato, Kenji Watanabe, Tokutaro Hayama \\ and Kenji Koyama \\ Department of Surgery (Director: Prof. T. Maki), \\ Tohoku University School of Medicine, Sendai
}

\begin{abstract}
The authors followed up, from six months to as long as 13 years and two months, a series of patients who had been splenectomized for Banti's syndrome at their surgical department. In succession to a number of papers that were published in this Journal, this communication deals with the postoperative change of plasma protein picture. The total protein level, which on many occasions had been below the normal range before splenectomy, tended to increase postoperatively; the average level was higher than the preoperative one not only at the time of discharge but also on follow-up study. Various favorable changes were also recorded in fractions of plasma protein, and the $\mathrm{A} / \mathrm{G}$ ratio was found to increase usually from a low preoperative value to approximate to the normal range by the time of long-term follow-up. On the basis of these results, the authors have concluded that splenectomy for Banti's syndrome has an effect to correct the abnormal plasma protein pieture in this syndrome.

A study on preoperative pattern of plasma protein in Banti's syndrome was reported in a previous paper. ${ }^{1}$ The present $\mathbf{r}$ pport discusses changes of plasma protein pattern in splenectomized cases with Banti's syndrome, particularly on the basis of long-term follow-up studies of the patients.
\end{abstract}

\section{MATERIALS AND METHODS}

Ninety-five cases in which the preoperative plasma protein study had been undertaken earlier ${ }^{1}$ were the subjects of present investigation. Following splenectomy, determination of plasma protein was achieved both at the time of discharge and follow-up. Postoperative hospitalization of these cases usually ranged between 21 and 40 days with the exceptional shortest record of 12 days and the longest of 118 days.

Follow-up cases were divided into four groups, namely, 17 cases examined between six months and two years, nine cases between two and five years, 12 cases between five and eight years and eight cases passed more than eight years postoperatively. Of these, the plasma protein determination was possible in 43 cases.

Received for publication, September 29, 1965

*The 11th Report of Studies on Banti's Syndrome. 


\section{RESULTS}

I. Changes in total plasma protein concentration

1. Total plasma protein concentration before splenectomy and at the time of discharge

Thirty-four cases were available for this study. Preoperative plasma protein determination of these 34 cases revealed that more than half of the cases, i.e., 19 cases $(55.9 \%$ ) had hypoproteinemia in contrast with 14 cases $(41.2 \%)$ with normal total plasma protein levels. The ratio, however, was reversed at the time of discharge, 25 cases $(73.5 \%)$ showing normal total plasma protein levels.

The mean total plasma protein concentration was $7.0 \mathrm{~g} / 100 \mathrm{ml}$ before splenectomy and $7.4 \mathrm{~g} / 100 \mathrm{ml}$ at the time of discharge suggesting that splenectomy could improve the hypoproteinemic condition up to within the normal limits, although there were two exceptional cases which showed a marked reduction even after splenectomy.

2. Total plasma protein concentration before splenectomy and at the time of followup

Thirty-seven cases were available for this study (Fig. 1). A group of 14 cases was followed up between six months and two years. Two cases with normal total plasma protein prior to splenectomy showed hypoproteinemia at the time of follow-up. Seven out of the 14 cases had hypoproteinemia after splenectomy, of

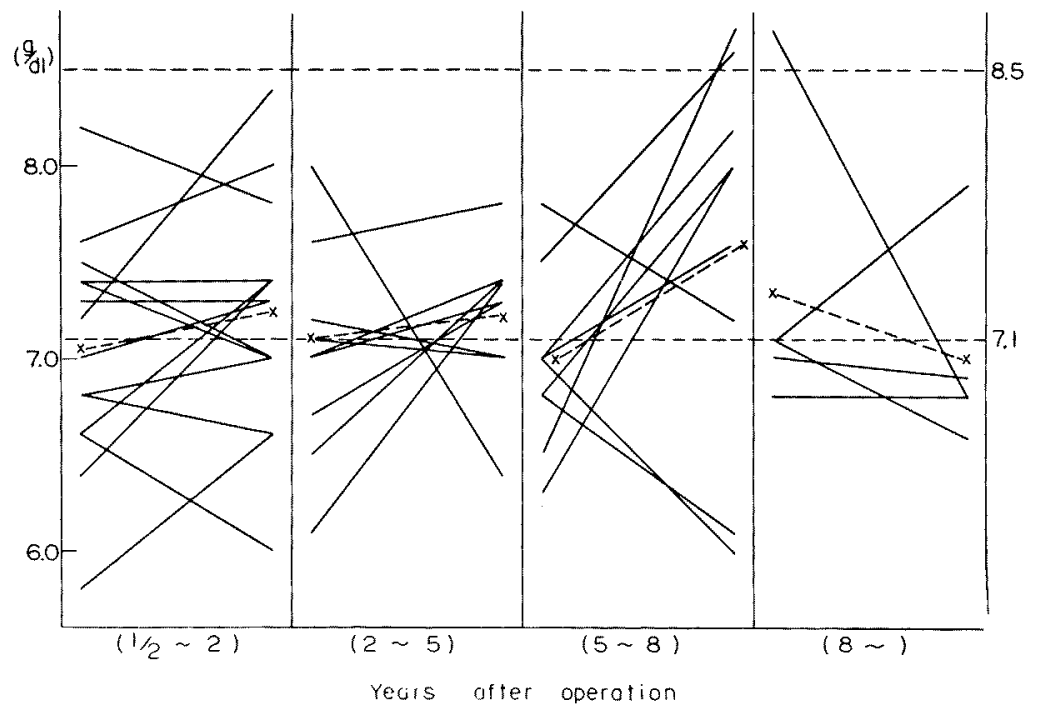

Fig. 1. Comparison of the total protein level between the preoperative time and the time of follow-up study. Grouped according to the period after splenectomy. $\times$ denotes the average value. 
which three cases showed normal values at the time of follow-up. The mean total plasma protein of these cases was $7.0 \mathrm{~g} / 100 \mathrm{ml}$ before splenectomy and $7.2 \mathrm{~g} / 100$ $\mathrm{ml}$ at the time of follow-up.

A group of nine cases was followed up between two and five years. Of these, three out of four cases which had normal total protein preoperatively showed lower values at the time of follow-up. In one case, marked reduction from 8.0 to 6.4 $\mathrm{g} / 100 \mathrm{ml}$ was noted, while a decrease in total plasma protein in the other two cases was of slight degree. Five cases with low preoperative total plasma protein showed an improvement, the level being within the normal limits at the time of follow-up in all these cases. In general, the cases of this group revealed a tendency toward increase of total plasma protein, the average level changing from 7.1 to $7.2 \mathrm{~g} / 100 \mathrm{ml}$.

A group of nine cases was followed up between five and eight years. Seven cases had low total plasma protein prior to operation. Three of these showed an improvement up to the normal value and one other case resulted in a marked increase from 6.5 to $8.7 \mathrm{~g} / 100 \mathrm{ml}$. Among the cases with low preoperative total plasma protein, two cases showed a marked decrease at the time of followup. As a whole, an increasing tendency in total plasma protein was noticed with a shift of the average from $7.0 \mathrm{~g} / 100 \mathrm{ml}$ of preoperative to $7.6 \mathrm{~g} / 100 \mathrm{ml}$ of follow-up.

Among the five cases followed up later than eight years postoperatively, one case which had had high total plasma protein prior to splenectomy showed a decrease to $6.8 \mathrm{~g} / 100 \mathrm{ml}$. Of the two cases with normoproteinemia preoperatively, one case was found to have low value at the time of follow-up. The mean value was $7.3 \mathrm{~g} / 100 \mathrm{ml}$ before splenectomy and $7.0 \mathrm{~g} / 100 \mathrm{ml}$ at the time of follow-up with an inclination of slight decrease.

Table 1 summarizes the shift of total plasma protein from the preoperative value through the time of discharge and follow-up. It will be noticed that the postoperative values generally exceeded the preoperative ones, although the values at the time of follow-up were slightly lower than at the time of discharge.

TABLE 1. Postsplenectomy changes in total plasma protein (mean values)

\begin{tabular}{l|c|c|c}
\hline & Before operation & On discharge & On late examination \\
\hline No. of cases & 77 & 35 & 40 \\
\hline $\begin{array}{l}\text { Mean value } \\
(\mathrm{g} / \mathrm{l} 00 \mathrm{ml})\end{array}$ & 7.05 & 7.44 & 7.28
\end{tabular}

II. Changes in albumin fraction

1. Albumin fruction before splenectomy and at the time of discharge

Blood samples for this comparative study were available from 15 cases. The 
number of cases with normal plasma albumin level (per cent of total protein) was only one before splenectomy and three at the time of discharge suggesting that the splenectomy had an effect in improving the level of albumin fraction. The albumin level averaged $46.1 \%$ before splenectomy and $48.6 \%$ at the time of discharge.

\section{Albumin fraction before splenectomy and at the time of follow-up}

Seventeen cases were available for this comparative study. The results are shown in Fig. 2. Of the 12 cases followed up between six months and two years, one case with normal preoperative level had low albumin level and one other case showed a considerable reduction from $52.0 \%$ to $36.7 \%$. The majority of the cases had kept low levels of albumin fraction, though there was an increasing tendency with three exceptional cases whose albumin fractions were corrected by splenectomy up to the normal range. The mean value was $46.8 \%$ before splenectomy and $50.9 \%$ at the time of follow-up.

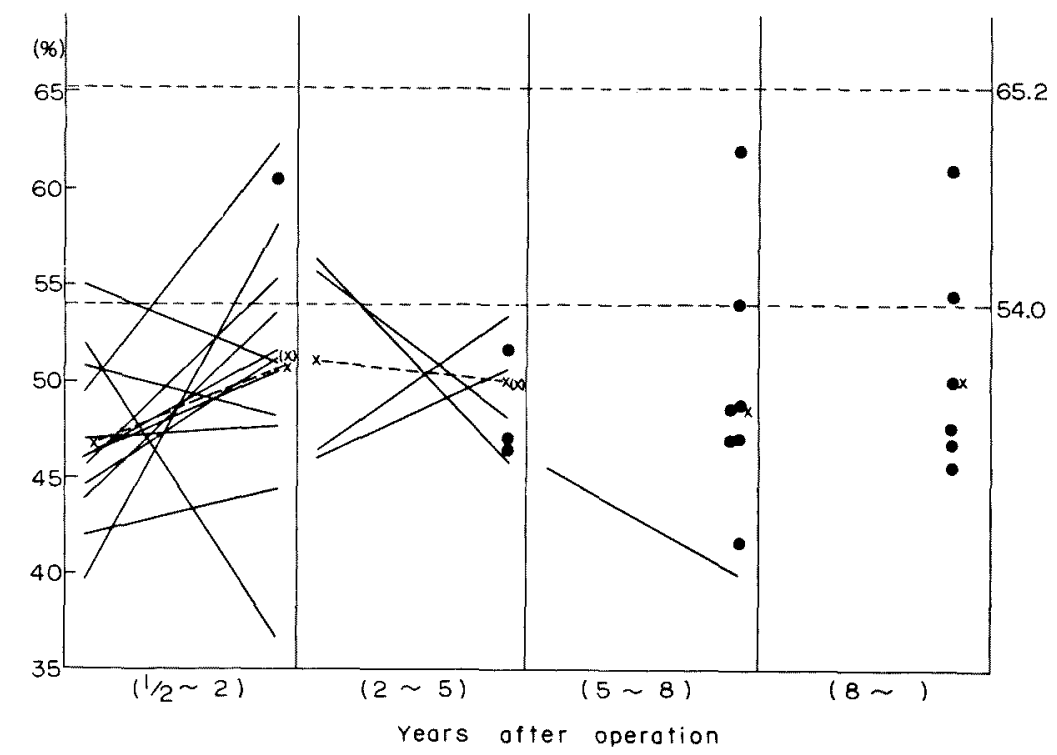

Fig. 2. Comparison of the relative albumin level between the preoperative time and the time of follow-up study. $x$ denotes the average value and $(x)$-the average postoperative value calculated taking into account the cases with unknown preoperative level.

Among the four cases followed up between two and five years, two cases which previously had normal albumin level showed low value, and two other cases with low levels preoperatively showed a slight increases. These results failed to show any uniform tendency presumably due to limited number of the cases, and none of these was found to have normal value. 
In one case which underwent splenectomy more than five years before, albumin level was $45.5 \%$ prior to operation and $39.9 \%$ at the time of follow-up.

The mean albumin fraction of each group at the time of follow-up was as follows. Since there were lack of cases in which the data of both preoperative and follow-up examinations were available, those in which albumin fraction was measured only at the time of follow-up were also taken into account.

The mean albumin level was $51.6 \%$ in the group of 13 cases examined between six months and two years following splenectomy, $49.0 \%$ in the group of seven cases from two to five years, $48.6 \%$ in the group of eight cases from five to eight years and $50.9 \%$ in the group of six cases examined later than eight years postoperatively. All of these exceeded the preoperative mean albumin level $(46.9 \%)$ of 43 cases with Banti's syndrome, although they did not reach the normal limits.

Shifts in mean albumin levels from preoperative to the time of follow-up are shown in Table 2. Namely, the level was $48.6 \%$ at the time of discharge and $50.2 \%$ at the time of follow-up, indicating a gradual increase in albumin fraction.

\section{Changes in alpha-globulin fraction}

\section{Alpha-globulin fraction before splenectomy and at the time of discharge}

Fifteen cases were available for this study. Alpha-globulin level (per cent of total protein) at the time of discharge was found to have no definite tendency, half of the cases showing a decrease and the other half an increase. Mean $\alpha$ globulin level was $10.7 \%$ prior to splenectomy and $9.1 \%$ at the time of discharge.

2. Alpha-globulin fraction before splenectomy and at the time of follow-up

Seventeen cases were available for this comparative study (Fig. 3). Of the 12 cases followed up between six months and two years, $\alpha$-globulin fraction was found somewhat increased in five cases in contrast with the other seven cases, which mostly showed a marked reduction. Of the four cases followed up between two to five years after splenectomy, one showed a remarkable increase from $5.5 \%$ before operation to a normal level $(7.7 \%)$ at the time of follow-up, but the other three exhibited a tendency toward postoperative decrease of the $\alpha$-globulin level. In one case, followed up between five and eight years, it was $7.7 \%$ before splenectomy which became $6.9 \%$ at the time of follow-up.

The mean $\alpha$-globulin levels calculated including the cases whose fractions were measured only at the time of follow-up were: $7.8 \%$ in 13 cases followed up between two and five years, $7.6 \%$ in eight cases between five and eight years. When these were compared with $10.5 \%$ of overall mean value of preoperative cases, there was noticed a tendency of decrease at the time of follow-up. Furthermore, the shift of the mean $a$-gloublin level from the preoperative to follow-up also revealed that the fraction could gradually be corrected into the 


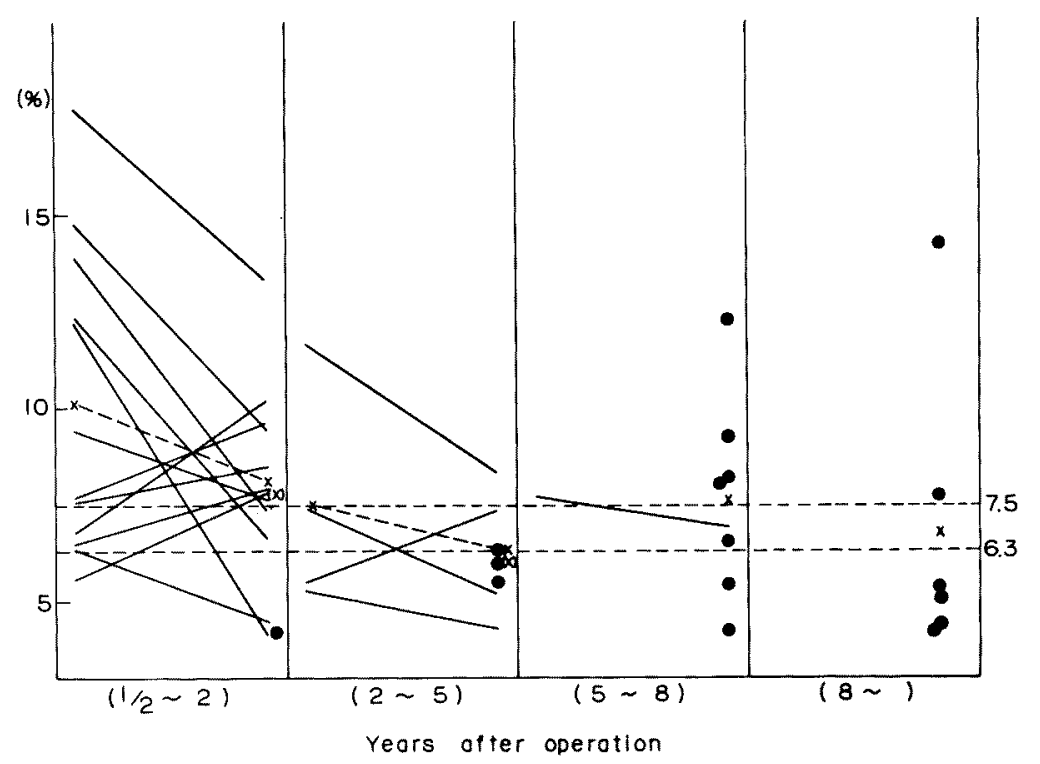

Fig. 3. Comparison of the relative a-globulin levels between the preoperative time and the time of follow-up study.

TABLE 2. Postsplenectomy changes in plasma protein fraction (mean values)

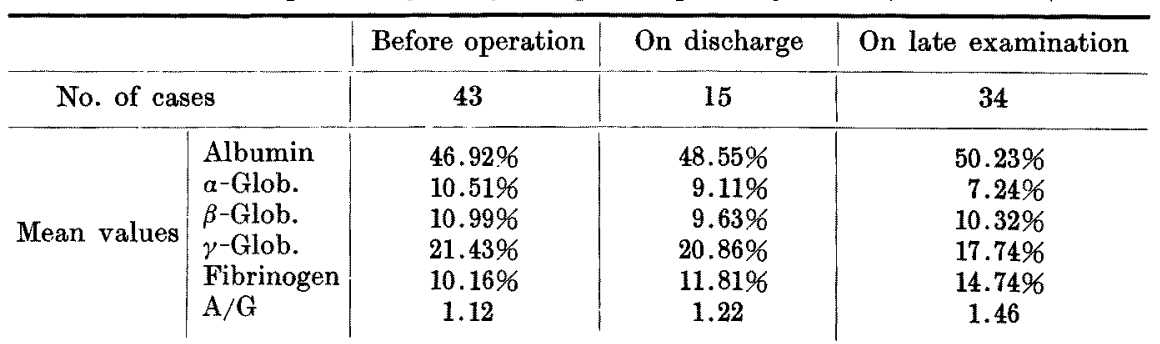

normal range by splenectomy (Table 2).

IV. Changes in beta-globulin fraction

1. Beta-globulin fraction before splenectomy and at the time of discharge

Fifteen cases were available for this comparative study. With an exception of one case whose preoperative low fraction level was improved to a normal level by the time of discharge, all the cases resulted in a reduction from $10.7 \%$ of preoperative mean value to $9.6 \%$ at the time of discharge. Of these, two cases with high fraction levels preoperatively turned to have normal levels and the three cases with normal fraction levels prior to splenectomy showed low level at the time of discharge. 


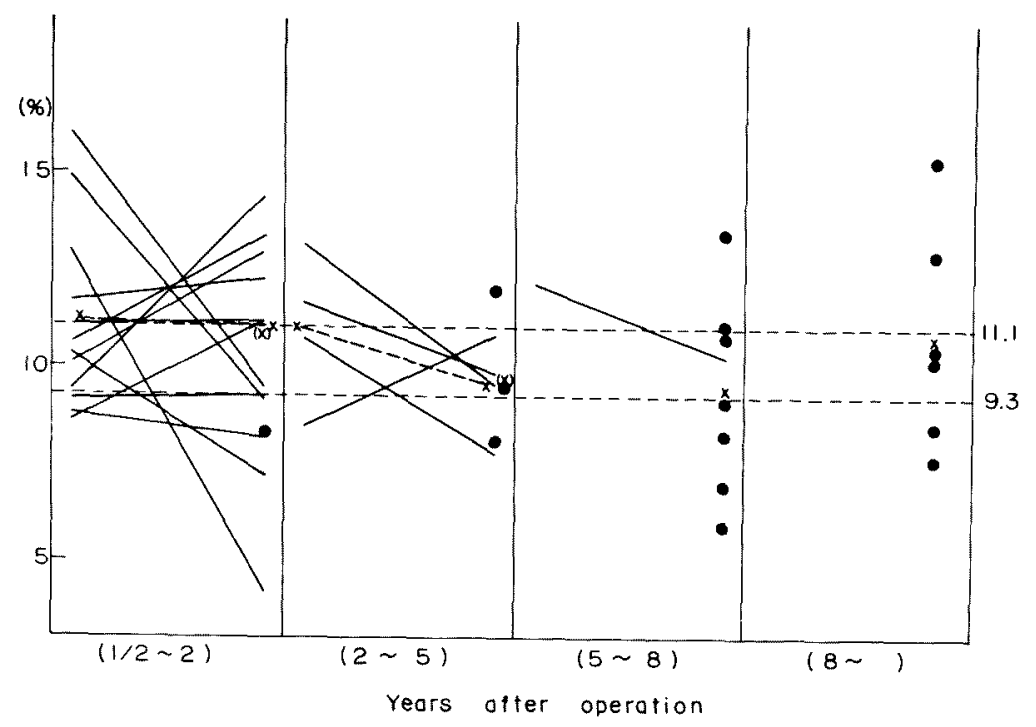

Fig. 4. Comparison of the relative $\beta$-globulin levels between the preoperative time and the time of follow-up study.

\section{Beta-globulin fraction before splenectomy and at the time of follow-up}

Seventeen cases were available for this comparative study (Fig. 4). Twelve cases followed up between six months and two years failed to show any definite changes of significance with $11.2 \%$ of mean fraction value before splenectomy and $11.1 \%$ at the time of follow-up. Of these, five cases had normal levels prior to operation which were reduced to two cases at the time of follow-up. Among the four cases followed up between two and five years, one case showed a normal fraction level preoperatively and three cases at the time of follow-up. Their mean fraction value slightly decreased from $11.1 \%$ to $9.6 \%$. One case followed up between five and eight years showed a high value preoperatively which became normal at the time of follow-up.

The mean $\beta$-globulin levels calculated including those whose fraction values were measured only at the time of follow-up were as follows: The mean fraction value was $10.9 \%$ in 13 cases which were followed up between six months and two years, $9.7 \%$ in seven cases followed up between two and five years, $9.5 \%$ in eight cases followed up between five and eight years and 10.9\% in six cases followed up later than eight years. These results indicated a decreasing tendency in $\beta$-globulin fraction from the preoperative mean value of $11.0 \%$ of 43 cases with Banti's syndrome. Table 2 shows the shift of mean $\beta$-globulin level from the time before splenectomy through the time of follow-up. As seen in the table, $\beta$-globulin fraction resulted in a decrease after splenectomy. 
V. Changes in gamma-globulin fraction

\section{Gamma-globulin fraction before splenectomy and at the time of discharge}

Fifteen cases were available for this comparative study. Among the cases which had high $\gamma$-globulin level prior to splenectomy, two cases showed normal levels at the time of discharge, e.g., in one case the fraction level decreased remarkably from $21.8 \%$ to $9.6 \%$. One case with normal fraction level before splenectomy had $14.2 \%$ of fraction value at the time of discharge. Other two cases, one with low and the other with normal levels preoperatively showed a remarkable increase up to $18.9 \%$ and $23.7 \%$ respectively. Thus, it was found that the splenectomy yielded no definite tendency in the shift of $\gamma$-globulin fraction in patients with Banti's syndrome and the changes in a mean fraction value was of no significance with $19.1 \%$ of preoperative and $19.5 \%$ at the time of discharge.

\section{Gamma-globulin fraction before splenectomy and at the time of follow-up}

Seventeen cases were available for this comparative study (Fig. 5). Of the 12 cases followed up between six months and two years, majority of the cases showed a tendency of decrease with an exception whose preoperative normal fraction value increased to $21.1 \%$ at the time of follow-up. Overall mean value was $19.3 \%$ before splenectomy and $17.3 \%$ at the time of follow-up. Four cases followed up between two and five years had high levels preoperatively with the average of $22.7 \%$. Of these, two cases had normal and the rest low levels at the

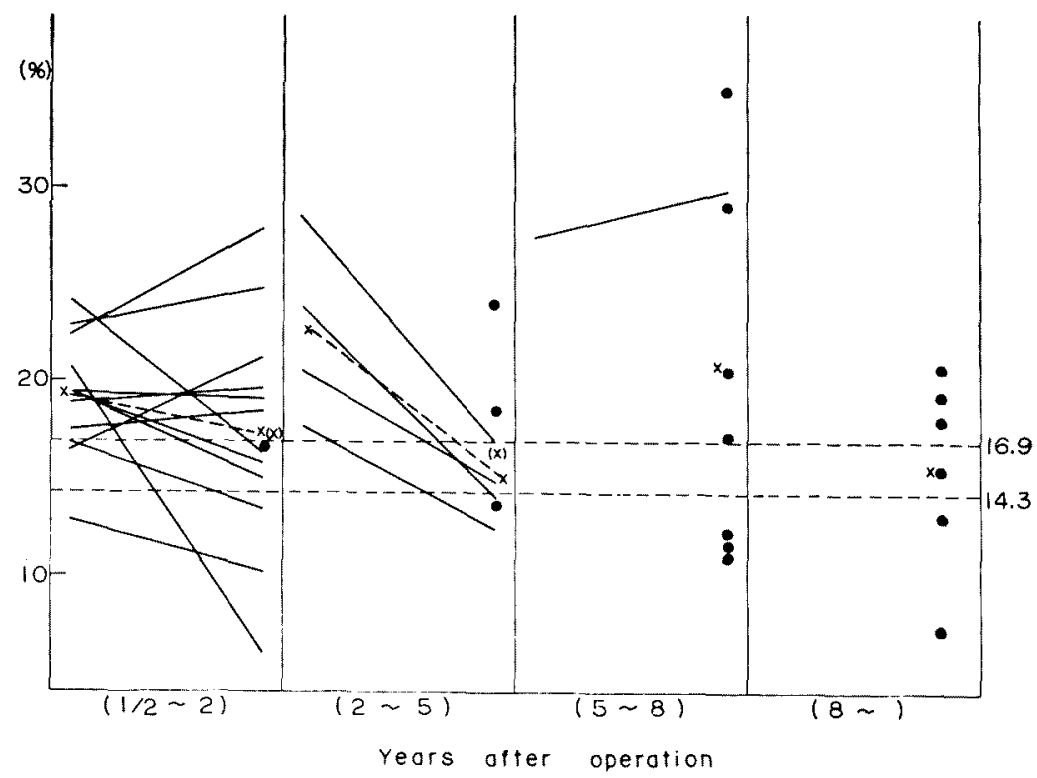

Fig. 5. Comparison of the relative $\gamma$-globulin levels between the preoperative time and the time of follow.up study. 
time of follow-up with the average of $14.5 \%$ which is considered to be within the normal limits. One case followed up between five and eight years showed little change in the fraction value.

Follow-up data of mean $\gamma$-globulin levels calculated including those whose fraction values were measured only at the time of follow-up were: $17.3 \%$ in 13 cases followed up between six months and two years, $16.3 \%$ in seven cases between two and five years, $20.8 \%$ in eight cases between five and eight years postoperatively. These results indicated a decreasing tendency when compared with the preoperative mean $\gamma$-globulin level of $21.43 \%$. Comparison of the mean fraction values among the preoperative, at the time of discharge and follow-up are shown in Table 2. It was revealed that $\gamma$-globulin gradually lessened following splenectomy, but could not be reduced lower enough within the normal limits.

VI. Changes in fibrinogen fraction

\section{Fibrinogen fraction before splenectomy and at the time of discharge}

Comparative study was made in 15 cases. Some showed a marked reduction and some resulted in an increase at the time of discharge without showing any definite tendency. The mean fibrinogen level was $12.8 \%$ preoperatively and $11.8 \%$ at the time of discharge failing to show any significant difference.

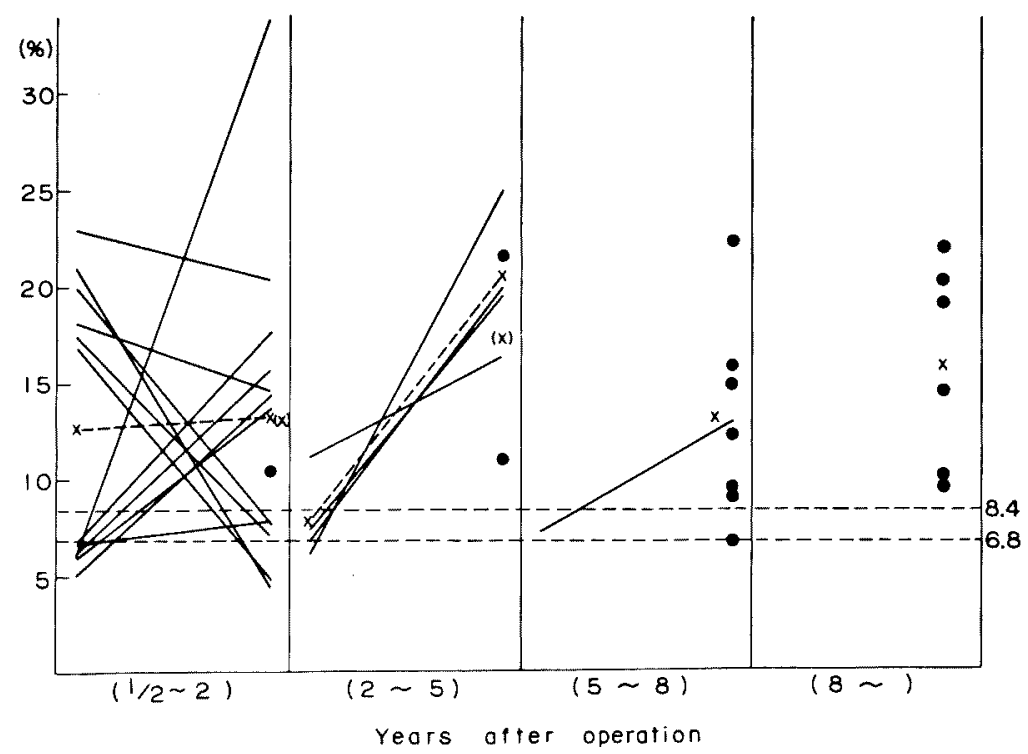

Fig. 6. Comparison of the relative fibrinogen levels between the preoperative time and the time of follow-up study. 
2. Fibrinogen fraction bejore splenectomy and at the time of follow-up

Seventeen cases were available for this comparative study (Fig. 6). Twelve cases followed up between six months and two years showed little changes in the mean fraction values, namely, $12.7 \%$ before splenectomy and $13.3 \%$ at the time of follow-up. All the four cases followed up between two and five years showed an increasing tendency with an average of preoperative $7.8 \%$ to $20.2 \%$ at the time of follow-up. One case followed up between five and eight years had normal fraction value preoperatively which became high at the time of follow-up.

Follow-up mean fibrinogen levels calculated including those whose values were measured only at the time of follow-up were: $13.2 \%$ in 13 cases followed up between six months and two years, $17.3 \%$ in seven cases between two and five years, $12.9 \%$ in eight cases between five and eight years and $15.9 \%$ in six cases followed up later than eight years after splenectomy. All of these were higher than $10.2 \%$ of preoperative mean fraction value of 43 cases with Banti's syndrome. The shift of mean fraction values from preoperative through the time of discharge to follow-up resulted in a gradual increase as seen in Table 2.

VII. Changes in $\mathrm{A} / \mathrm{G}$ ratio

1. A/G ratio before splenectomy and at the time of discharge

Fifteen cases were available for this comparative study. The ratio increased in eight cases and decreased in seven cases by the time of discharge. Of the 13 cases which had low A/G ratio preoperatively, two cases showed higher ratio, while the remaining cases stayed within the range of low $A / G$ ratio. However, the mean ratio slightly increased from 1.1 to 1.2 with a sign of little improvement.

\section{A/G ratio before splenectomy and at the time of follow-up}

Seventeen cases were available for this comparative study (Fig. 7). Of the 12 cases followed up between six months and two years, five cases still showed low ratio. The remaining cases resulted in a marked increase, e.g., the number of the cases with normal ratio increased from two to five cases. The preoperative mean $\mathrm{A} / \mathrm{G}$ ratio was low being 1.1 which became a normal value of 1.4 at the time of follow-up. Four cases were followed up between two and five years. of the two cases with low ratio before splenectomy, one case had normal and the other had somewhat higher ratio at the time of follow-up. Two cases with normal ratio preoperatively showed little change at the time of follow-up. The mean ratio was 1.3 before splenectomy and 1.6 at the time of follow-up indicating there had been a marked improvement. One case followed up between five and eight years remained unchanged, staying below normal.

Follow-up mean $\mathrm{A} / \mathrm{G}$ ratios calculated including those whose ratio was measured only at the time of follow-up were: 1.5 in 13 cases followed up between six months and two years, 1.5 in seven cases between two and five years, 1.3 in eight cases between five and eight years and 1.6 in six cases followed up later than 


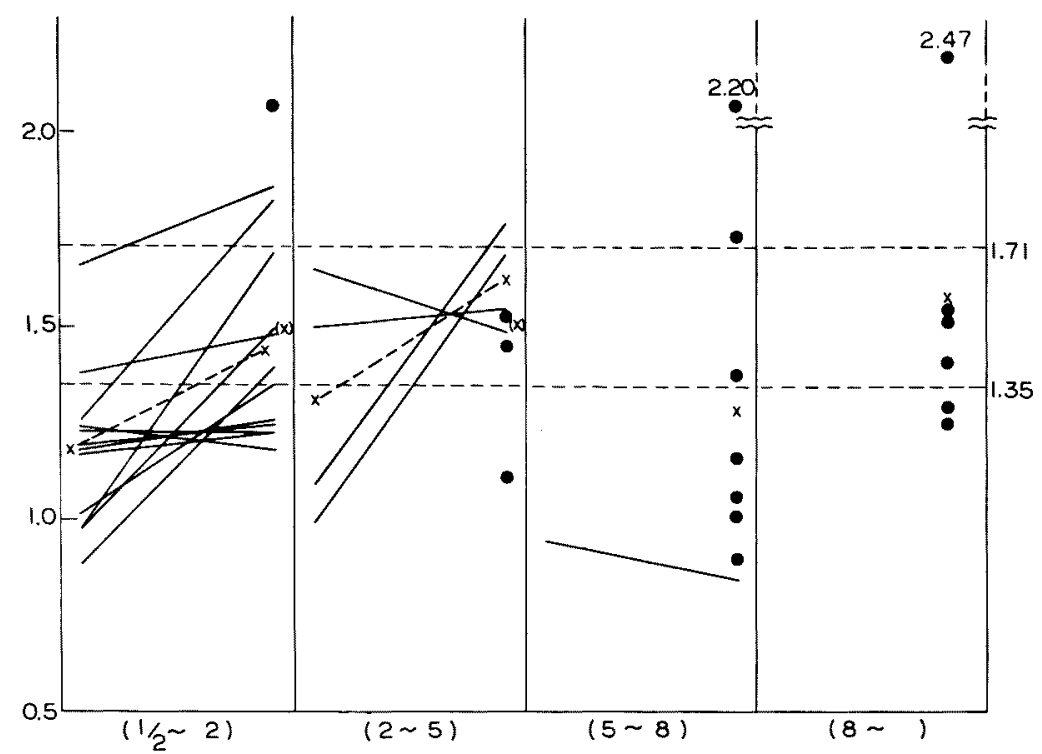

Fig. 7. Comparison of the $A / G$ ratio between the preoperative time and the time of follow-up study.

eight years after splenectomy. All of these exceeded the preoperative level of 1.1 with considerable differences. $\mathrm{A} / \mathrm{G}$ ratios before splenectomy, at the time of discharge and follow-up are shown in Table 2. It has been revealed that the ratio gradually increases following splenectomy.

\section{DISCUSSIONS}

Few reports have ever described in detail about plasma protein in so-called Banti's syndrome. Furthermore, as far as the authors' knowledge concerns, there has not been found any report which traced in detail the changes in plasma protein and its fractions after splenectomy. In succession to the series of previous studies reported from our Department, the present authors studied the changes in plasma protein in 95 cases operated upon for Banti's syndrome, both at the time of discharge and follow-up.

As to the changes in total plasma protein after splenectomy, Suzuki² observed that the majority of the cases resulted in a decrease, while Shibata ${ }^{3}$ and $\mathrm{Kunii}^{4}$ obtained an opposite result of an increasing tendency. The present study has revealed that the total plasma protein tends to increase following splenectomy. The fact that the total plasma protein was higher at the time of discharge than at the time of follow-up may be elucidated by the effects of blood transfusion or some other fluids therapy during the convalescent period.

In regard to the changes in albumin fraction after splenectomy, Araki ${ }^{5}$ 
observed a decreasing tendency shortly after splenectomy, whereas Miwa ${ }^{6}$ reported that the albumin fraction became normal during the postoperative observation from three to six months. On the other hand, Takatsuki ${ }^{7}$ failed to confirm any definite tendency. According to our data obtained from 15 cases, it was shown that the albumin fraction steadily increased following splenectomy, though it did not reach the normal range.

As to the postsplenectomy changes in $\alpha$-globulin fraction, Araki ${ }^{5}$ noticed that, except a few cases in which the fraction increased, a-gloublin fraction in most of the cases failed to show any noticeable changes during the observation period up to a few weeks. Miwa, ${ }^{6}$ on the basis of his follow-up study from three to six months after splenectomy, reported that $\alpha$-globulin fraction increased and almost reached the upper normal limit. In our series, however, the postsplenectomy fraction value gradually tended to decrease with its mean value approaching to the normal range.

Concerning the postsplenectomy changes in $\beta$-globulin fraction, Araki ${ }^{5}$ observed little changes in a period of a few weeks, while Miwa ${ }^{6}$ pointed out a tendency of slight increase up to the upper limit of the normal range. Our data indicated a decreasing tendency of slight degree at the time of discharge, and although its mean value decreased postoperatively, the changes were quite limited without any significance.

As to the postsplenectomy changes in $\gamma$-globulin fraction, Araki ${ }^{5}$ through a few weeks' observation and Miwa out of an observation between three and six months noticed further increase. Goto ${ }^{8}$ in his follow-up study with 21 cases also found an increasing tendency in a few cases. On the contrary, Suzuki ${ }^{2}$ observed an opposite result of decreasing tendency. Our data suggested that there were no definite changes at the time of discharge, but the fraction value showed a decreasing tendency at the time of follow-up. Mean $\gamma$-globulin fractions also resulted in a gradual decrease though they remained higher than normal.

As to the postsplenectomy changes in fibrinogen, Araki ${ }^{5}$ noticed no obvious changes within a few weeks' observation. Although our data also failed to show any significant tendency, the mean fibrinogen value was found slightly increased both at the time of discharge and follow-up.

As to the postsplenectomy changes in $A / G$ ratio, Araki ${ }^{5}$ out of the observation within a few weeks and $M^{2}{ }^{6}$ from three to six months observation still noticed a decreasing tendency. Our data in 15 cases measured at the time of discharge did not show any variations except a tendency of slight increase. Long time follow-up in 19 cases indicated that, with the lapse of time, A/G ratio tended to be improved close to the normal range with the ratio of 1.1 before splenectomy, 1.2 at the time of discharge and 1.5 of the normal ratio at the time of follow-up.

The above reported are the results and influences of splenectomy on the 
protein metabolism in Banti's syndrome particularly on the changes in plasma protein pictures. At our Department, serial studies have been made in detail as to the postsplenectomy changes in blood picture, liver function, hepatic histology and esophageal varices which, taken together. have led to the conclusion that the splenectomy is highly effective for Banti's syndrome. Out of these results, we have reported several times that the splenic factors are of great significance in the pathogenesis of Banti's syndrome. ${ }^{9-14}$

The present investigation on the postsplenectomy changes in plasma protein picture has revealed that the total plasma protein tends to increase following splenectomy, in most of the cases reaching the normal limit. Albumin fraction as well as $A / G$ ratio could also be corrected into the normal ranges. As to the changes in plasma protein fractions, although the definite conclusion is far from clear due to the lack of cases in which the plasma protein fractions could be measured both before splenectomy and at the time of follow-up, the tendency has been noticed that the splenectomy was effective in improving the value of each plasma protein fraction.

\section{Reference}

1) Sato, T., Uchiyama, S., Hayama, T. \& Koy.ıma, K. Plasma protein pattern in Banti's syndrome. Tohoku J. exp. Med., 1965, 87, 358-365.

2) Suzuki, T. Plasma protein pattern in so-called Banti's syndrome. Nippon Geka Gakkai Zassi (Jap.), 1961, 62, 894.

3) Shibata, H. Long-term observation on liver function in Banti's syndrome after splenectomy. Iryo (Jap.), 1959, 13, 772-783.

4) Kunii, K. Long-term observation of Banti's syndrome after splenectomy. Saishin Igaku (Jap.), 1962, 17, 230.

5) Araki, Y. On the correlationship between the changes of hematopoietic organs and plasma proteins in hepatolienal diseases. Tokyo Igaku Zasshi (Jap.), 954, 62, 145162.

6) Miwa, S. Clinical observation of Banti's syndrome. Nippon Ketsuekibyo Gakkai Zasshi (Jap.), 1961, 24, 254-255.

7) Takatsuki, S. Electrophoretic studies of blood serum proteins in hepatobiliary disease. Naikahokan (Jap.), 1959, 6, 255-258.

8) Goto, H. Hematological studies on the long-term effects of splenectomy in Banti's syndrome. Kyushu Ketsueki Kenkyukai Zasshi (Jap.), 1961, 11, 224-267.

9) Sato, T., Kakizaki, G., Saito, Y. \& Seki, K. Studies on Banti's syndrome. I. Mortality and survival after splenectomy. Tohoku J. exp. Med., 1963, 80, 18-25.

10) Sato, T., Koseki, K., Watanabe, K. \& Miya, M. Studies on Banti's syndrome. II. Effect of splenectomy on hematology. Tohoku J. exp. Med., 1963, 80, 237-253.

11) Sato, T., Watanabe, K., Miya, M. \& Ottomo, M. Studies on Banti's syndrome. III. Effect of splenectomy on increased portal pressure and its manifestations. Tohoku J. exp. Med., 1963, 80, 254-267.

12) Sato, T., Watanabe, T., Saito, Y. \& Seki, K. Prognosis of Banti's syndrome viewed from histopathology and functions of the liver. TohokuJ.exp. Med., 1963, $81,1-16$.

13) Sato, T., Takahashi, M., Suda, Y. \& Watanabe. T. Effect of splenectomy on histopathology and functions of the liver in Banti's syndrome. Tohoku J. exp. Med., 
$1963,81,17-45$.

14) Sato, T., Kakizaki, G., Abe, Y. \& Uchiyama, S. Factors influencing portal pressure in Banti's syndrome. Tohoku J. exp. Med., 1963, 81, 122-137. 